\title{
Un soneto de Darío que no es de Darío
}

$\mathrm{H}^{\mathrm{N}}$ I934, a poco de estar en Chile, Augusto d'Halmar proyectó una manejada entonces por su fundador, Laureano Rodrigo. Según el prospecto que hubo de publicarse para esta iniciativa, las obras quedarian agrupadas en veinticinco volúmenes, que no es el momento de indicar por separado. El prospecto es un folleto de treinta y dos páginas sin numerar, sin fecha de impresión, pero no anterior a I935, donde se reproducen opiniones de diferentes escritores sobre D'Halmar y sus obras. En las páginas que podríamos numerar I6 y I7 se leen, bajo el rubro general de "Retratos Imaginarios", dos composiciones poéticas, una titulada "Don Augusto d'Halmar" y otra "A D'Halmar", la primera con la firma al pie de Rubén Darío y suscrita la otra por Amado Nervo.

El soneto de Darío a que se referirán las observaciones agrupadas en seguida es muy conocido, pero conviene repetirlo esta vez por la necesidad en que nos hallamos de aducir algunas de sus expresiones textuales en la discusión. Dice así:

Como Píndaro, tiende hacia el viento que sopla la vela de su nave, que es una carabela de Cortés por lo audaz y de Constantinopla, de París y de la India. Su palabra, que vuela,

Sutilmente, recuerda la más cálida copla de España. Su ascendencia un gran misterio vela. QQuién sabe cuál caballo dominó su manopla! ¿Quién sabe los encantos que su sonrisa anhela!

Encaneció muy joven, viłió su hora intensa, ebrio de hallar su vida por tan humana inmensa, $\gamma$ adolescente supo de las iras del mar. 
Por eso, cuando muera dirá la Fama: "Nunca fue una vida tan bella, a pesar de ser trunca, como la de este nómade don Augusto d'Halmar!"

Estos versos eran ya conocidos del público chileno, pues $E l$ Mercurio de Santiago, en su edición de i I de abril de I922, había publicado una información que los contenía. En la página de redacción de ese diario se leía "Un escritor chileno en Madrid", y como subtítulo "Homenaje a D'Halmar", nota para dar cuenta de una velada en el Ateneo de Madrid, en el curso de la cual saludó al escritor chileno el español Antonio Espina. El propio Espina leyó aquellos dos poemas en celebración de D'Halmar atribuidos a Rubén Darío y a Amado Nervo. El cuerpo de la información constaba de un oficio enviado por el Ministro de Chile en Madrid, don Joaquín Fernández Blanco, muy elogioso para el escritor chileno, y del discurso de Espina, transcrito en texto íntegro. Cabe recordar que los versos de Darío muestran algunos ligeros cambios que juzgamos erratas mecánicas y no variantes.

Esta publicación de los versos atribuidos a Dario y a Nervo, que juzgamos por ahora ser la primera hecha en Chile, es posterior a la muerte de aquellos dos escritores: Darío falleció en I9I6 y Nervo en I9I9.

En años siguientes, D'Halmar ofreció en el salón central de la Universidad de Chile una conferencia, con el título de "Rubén Darío y los americanos en París", publicada en folleto que lleva el mismo nombre (I94r) ;* y allí volvía a leerse el soneto ya referido, dentro de la página I3, con algunos trueques. Al copiarlo, más arriba, hemos tratado de concordar las dos versiones para que la lectura sea más despejada. El' estudio de las vatiantes, si existen, no hacen en absoluto a la cuestión que deseamos plantear en este artículo.

*[Debe ser una tirada aparte de los Anales de la Universidad de Cbile, 1er. trimestre de 1941, año XCIX, $\mathrm{N}^{\circ}$ 41, 3a. serie, pp. 7.14, donde aparece dedicada a Eugenio Orrego Vicuña, y como homenaje a Darío en el XXV aniversatio de su muerte. En el mismo número se publica "El Alba de Oro", de Eugenio Orrego Vicuña, "comedia poética en cuatro jornadas", pp. 46-192, con cierta intención histórico-biográfica, pues en la "jornada tercera" que se desarrolla en "las oficinas de Mundial, en Paris... tarde un día de Agosto de 1914", figura D'Halmar como interlocutor de Darío (esc. III, IV y VII) y en un parlamento de éste se menciona a Luis Orrego Luço, padre del autor. El hecho de que Darío ya estuviera en Barcelona desde junio de 1914 quita toda verosimilitud a este encuentro teatral con D'Halmar, y ino sería planeado todo este infundio, inclusive el soneto, entre Orrego Vicuña y D'Halmar? Por otra parte, la conferencia de D'Halmar se publicó también en Revista Aduand, Valparáiso, junio-septiembre de 1942, año IV, No. 39, pp. 13-16, y el "Soneto a D'Halnnar" en Nuevo. Mundo, Madrid, 11 de julio de 1924; clipping en. The Hispanis Society of Ametica, Nueva York]. 
En aquella conferencia, Augusto d'Halmar contó su amistad con Darío en Paris y las circunstancias en que habría sido producido aquel soneto. Apartando pormenores de otra índole, la escena queda relatada en los términos siguientes:

Acudí cierta noche a despedirme de la tertulia, porque al día siguiente debía irme de París, no sé dónde. Sólo hallé a Amado Nervo y a Darío y les conté mi viaje.

- ¿Qué harás - me interrumpió Rubén- de aquel vino que tú llamabas "terciopelo de los dioses"?

-Quedar pocas botellas. Se las dejaré a mi portera.

- iNo en mías días!-protestó mi interlocutor. Nos las beberemos juntos y te haremos compañia hasta que mañana salga tu tren.

Así se hizo. En aquel quinto piso del Muelle de los Celestinos, con vista al Sena y a la Isla San Luis, que después heredó Jean Cassou y donde tantas veces acudió, entre otros, don Miguel de Unamuno, hicimos sendas fogatas con toda la leña que quedaba; pusimos en baño de María una media docena de Medoc, abrimos conservas y, mientras yo departía con Nervo ante la chimenea de mi escritorio, ante la de mi pieza se quedó Rubén ensimismado; de pronto le vimos irrumpir y nos leyó un soneto que me dedicaba y que, al visitar los campamentos durante la guerra de Âfrica, me hallé pegado en recorte en una tienda de campaña, donde los aburridos soldaditos se lo habian aprendido de memoria, unos tras otros, con apuestas de quién se la ganaba a quién (Obra cit., pp. 12-13).

Y copió el soneto sobre el cual versan estas apuntaciones. Hasta allí lo que nos interesa de aquella cvocación. El objeto de este artículo no es otro que probar, con todos los documentos que nos son accesibles después de larga pesquisa, los siguientes puntos:

I. La entrevista de Augusto d'Halmar con Rubén Dario a que se refieren esas líneas, jamás existió. Dicho de otra suerte: el escritor nicaragüense y el escritor chileno no se encontraron nunca, y no pudieron por tanto tener la tertulia a que se tefiere el segundo ni la entrevista final en el departamento del muelle de los Celestinos.

2. En consecuencia, el soneto atribuido a Darío y que Augusto d'Halmar publicó con esa firma, no ha podido ser escrito por Rubén Datío.

Vamos a las pruebas.

El punto I nos obliga a contar algo de lo que sucedió con Augusto d'Halmar en los días finales de 1907 , fecha en la cual inició éste su primer viaje al extranjero, a raíz de haber sido nombrado Cónsul de Chile en Calcuta. Embarcó el viajero en Valparaíso en el mes de noviem- 
bre de 1907, y según relata él mismo en sus Recuerdos olvidados (serie de artículos publicados en La Nación de Santiago desde el 28 de junio de 1939), estaba en Londres el día 29 de diciembre de 1907 . De ahí pasó a París, a donde hubo de llegar, como es de cajón, en los primeros días de 1908. Rubén Darío entonces no se encontraba en la capital de Francia, ni siquiera en Europa, pues se había embarcado el 25 de octubre de 1907 con rumbo a su tierra natal. Permaneció alli, en Nicaragua, hasta el mes de abril de I908, y sólo en el mes de mayo estaba nuevamente en Europa. No creo necesario documentar especialmente estos desplazamientos, desde que la biografía de Darío es bien conocida. De todos modos, debe señalarse que estas fechas pueden hallarse con suma facilidad en el libro que publicó en seguida Darío, El vidje a Nicaragua (I909), donde narra las fiestas con que fue agasajado en su patria. Idéntica observación puede hacerse sobre la biografía de Rubén Darío que debemos a Edelberto Torres, La dramática vida de Rubén Dario (Segunda edición: México, 1956), donde las fechas pertinentes se hallan no sólo en el capítulo XVI, "La apoteosis en su Jerusalén" (pp. 222243), sino también en la cronología que da en la misma obra. Finalmente, si se sigue la colaboración de Datío en La Nación de Buenos Aires, bien podrá verse desde dónde escribía el poeta, y cómo en el periodo de diciembre de 1907 -mayo de 1908 no vivió en París sino en Nicaragua.

Bien; quedamos en que Darío y D'Halmar no se hallaron en París en esta ocasión, por imposibilidad absoluta, ya que el poeta nicaragïense no estaba entonces allí.

Augusto d'Halmar siguió viaje a la India para hacerse cargo de su consulado, después de pasar algunos días en París, pero por motivos de salud hubo de permanecer muy poco tiempo en su sede. Contaba él que había tenido una gravísima enfermedad cutánea, y que salvó de la muerte sólo por milagro y que en vista de la experiencia no pensó en otra cosa sino en huir cuanto antes de la: India. Este punto, por lo demás, ha sido narrado por el propio escritor, de modo que podemos cederle la palabra para conocer su versión. En un artículo especial para la revista chilena En viaje, titulado "Un chileno en el Perú", se leen estas expresiones:

En 1908, o sea hace treinta y seis años, el Cónsul General de Chile en la India y posesiones inglesas en el Asía, según rezaba su exequatur, enfermo en Calculta y aterrado por la inhumana y perenne canícula del clima, sin esperar licencia se embarcó para Europa. Era escritor y contaba vivif en Patis un par de años con sus recursos; después, Dios dirîa. 
Pero sus admiradores chilenos hicieron antesala en la Moneda hasta que el Canciller destinó a aquel impresionable funcionario al Consulado en Chiclayo, rebajándolo de categoría para sancionar en alguna forma su deserción.

Así reembarcó hacia América cuando aun no se abría el Canal; tuvo en Panamá una fiebre más o menos amarilla, y después de haber cenocido el lazareto de Colón y de haber representado oficialmente a su gobierno en la transmisión del mando del Presidente Arozamena, siguió hasta Eten (En viaje, abril de 1945, pp. 77-8).

Estas palabras hacen alusión a las gestiones que hubieron de hacer los amigos del autor para conseguirle nuevo nombramiento. E1 Ministerio de Relaciones Exteriores lo expidió en la forma que sigue:

Miristerio

de Relaciones Exteriores

Santiago, 24 de Junio de 1908.

No 666

He acordado y decreto:

Nómbrase al actual Cónsul Particular de Profesión en Calcuta, don Augusto Thomson, para que sirva igual cargo en Chiclayo, que se encuentra vacante por renuncia de la persona que lo servía.

Extiéndasele al nombrado las Letras Patentes respectivas.

Tómese razón, regístrese y comuniquese.

Mont't-F. Puga Borne.

Debe notarse, pues, que D'Halmar emprendía viaje de regreso al continente americano en el curso de junio de rgo8, para irse a desempeñar el puesto de Cónsul en Chiclayo, en la costa peruana. ¿Hasta cuándo permaneció allí? Muy fácil establecerlo por los dos documentos que en seguida copiamos. Es el primero la petición de licencia que hace el cónsul y es el segundo el decreto por el cual se declaró vacante su empleo.

La petición dice asi:

Consulado de Chile en Chiclayo

Eten

Anexo a la nota $N^{\circ}$ 8.-S.C.

Pto. Eten (Perú) 31 de Enero 1916.

Señor Ministro:

Necesitando acogerme a la licencia consular, de la cual no he hecho uso en los ocho años y meses que cuento en el servicio, tengo el honor de solicitar de US. se sirva concedérmela.

Por tratarse de un permiso al cual tenía derecho con antelación a la 
nueva Ley, agradecería me fuere otorgado, por justicia o por gracia, en los términos que señala la antigua, es decir por seis meses a contar desde mi arribada a esa, deseando por motivos particulares poder embarcarme aquí a fines de Marzo del presente año o sea del primer trimestre de rendición de cuentas.

Para lo cual estimaría igualmente a US. que tomase las disposiciones del caso ó impartiese oportunamente sus instrucciones al Sr. Cónsul General, cuya aprobación he consultado previamente y por cuyo intermedio elevo la presente -á fin de que coincida en esta fecha de 31 de Marzo, la llegada de la persona que debe reemplazarme durante mi ausencia.

Dios guarde a Us.

\section{Augusto Tbomson}

Cónsul.

El decreto reza como sigue:

Ministerio de Relaciones

Exteriores

Santiago, 28 de Setiembre de 1916.

No 1151. Teniendo presente:

$1^{\circ}$-Que por decreto № 283 de 13 de Marzo último, se concedió licencia de cuatro meses, a contar desde el $1^{\circ}$ de Abril, al Cónsul de Chile en Chiclayo don Augusto Thomson; y que dicho funcionario no reasumió su puesto después de expirada esta licencia,

\section{DECRETO:}

Déclarase vacante el cargo de Cónsul Particular de Profesión en Chiclayo, Perú, servido por don Augusto Thomson, y se nombra en su reemplazo a don Raimundo Charlin Correa.

Cancélense las letras patentes del señor Thonson y extiéndasele nuevas letras patentes al nombrado señor Charlin.

Tómese razón, regístrese y comuniquese

SANFUENTES,-J.E. Tocornal.

Estos documentos oficiales proceden del Archivo Nacional, donde fueron copiados para el autor de esta nota por orden de don Juan Eyzaguirre, director de aquel servicio.

Vamos ahora recapitulando algunos indicios útiles.

En el documento de 3 I de enero de igr6, Thomson (d'Halmar) afirma no haber hecho uso de licencia "en los ocho años y meses" que lleva en el servicio; con lo cual queda perfectamente en claro que en ninguna fecha comprendida entre enero de r9o8 (cuando pasó por París, y Darío no estaba allí) y enero de I9r6, hizo viaje que le permitiera encontrarse con Darío, ni en la capital de Francia ni en otro 
sitio alguno. Debe fijarse la atención en que esta imposibilidad de encontrarse los dos escritores ha de comprender asimismo el viaje que Rubén Darío hizo al continente americano en el curso de I9r2, ocasión en la cual se quedó en Buenos Aires sin pasar a Chile, como tenía anunciado. Debe entenderse, pues, insistimos, en que según declaración propia y espontánea de D'Halmar, él no había hecho viaje alguno entre las fechas que ya dejamos indicadas.

Pero detengámonos ahora en la fecha de aquel documento. Es del $3^{1}$ de enero de rgr6, cuando Rubén Darío, gravemente enfermo, esperaba la muerte en Nicaragua, la cual en fin cortó su vida el día 6 de febrero de I9I6.

Augusto d'Halmar era afecto a escribir de memoria y sin cuidarse mucho de la coherencia de sus recuerdos, porque existe un muy curioso artículo de él, "Veinte años después", publicado en el diario La Hora, de Santiago, el $\mathrm{I}_{4}$ de febrero de I936. Dice alli:

Nos habíamos separado en París y yo sabía, vagamente, desde el Perú, que también Dario habia abandonado Europa.

Dentro del mismo artículo se lee también:

$\mathrm{Y}$ desde Eten, del Perú, yo supe por el cable del universo la noticia [la muerte de Dario]. Y una semana más tarde me trajo el correo una carta suya. Era como si me la enviara desde el Más Allá. Como si me recordara la convocatoria que, para un plazo incierto pero inaplazable [inacsptable dice en el diario, por errata], me hizo nuestro común Amado Nervo, un día del tiempo, en que los tres estábamos reunidos y nos sentíamos vivientes y aún jóvenes:

Yo te emplazo en una cita

sobre la arena infinita sideral...

Esta pretensión de haber recibido una carta de Rubén Darío, escrita en la agonía, es cuanto cabe de peregrino. Debe recordarse que Darío salió de Europa, rumbo a los Estados Unidos, en octubre de I9r4, cayó gravemente enfermo en Nueva York, en diciembre de ese año, y apenas convaleciente se trasladó a Guatemala, donde estaba en abril de I9r5; que en seguida sale de allí y se va a su tierra, alcanzando el puerto de Corinto el 25 de noviembre de 1915. Omitiendo detalles, Dario está enfermo de muerte y desde esta fecha hasta la de su deceso no pudo, según consta de todos los testimonios accesibles, levantar cabeza para cosa alguna. ¿Puede alguien imaginar que en semejante estado de postración iba a escribir una carta a D'Halmar, quien puede haberle caído muy 
en gracia - si alguna vez lo vio - pero no pasaba de ser uno de tantos, en la enorme lista de escritores a quienes hubo de tratar en sus peregrinaciones? Yo creo que esta vez, es decir, en el artículo de La Hora, D'Halmar fantaseaba y decía lo que no era cierto.

Pero lo más chusco de la cosa está en que dentro de ese artículo destinado a conmemorar los veinte años corridos de la muerte de Darío, D'Halmar se olvida total y completamente del famoso soneto que había atribuido a éste, a pesar de ser ella una ocasión bien sonada para rememorarlo, y en cambio recuerda los versos atribuidos a Nervo. ¿No será este singular olvido una de esas equivocaciones que llamamos freudianas, por haber sido Freud quien señaló su efectivo significado?

Volviendo al tema central de esta dicusión, vamos a dar al lector nuevas oportunidades para que entienda a fondo el problema, hilarante sin duda pero también grotesco. Dejamos ya a D'Halmar en viaje a Calcuta, donde iba a tomar el cargo de cónsul, y dijimos que en esa primera pasada por París, en los inicios de r908, el escritor chileno no pudo ser amigo de Darío, por un motivo muy sencillo pero irrefutable: porque Darío se hallaba, desde octubre de 1907 , fuera de la capital francesa, y en concreto en Nicaragua. En Calculta, repetimos, D'Halmar cayó enfermo, y de tal índole fue este accidente que los diarios de Chile informaton sobre él. El Mercurio, de Santiago, en su edición de I8 de junio de I908, decía:

Telegramas recientemente llegados hacen saber que se halla enfermo de gravedad en Calculta el cónsul de Chile en esa. ciudad, señor Augusto Thomson.

El decreto que le nombró en Chiclayo tiene fecha 24 del mismo mes de junio. Puede, en fin, suponerse que D'Halmar, en el viaje de regreso a América, ha podido estar en París entre los meses de junio y agosto de I908. ¿Encontró entonces a Rubén Darío? Imposible, por la muy sencilla razón de que el poeta esta vez tampoco vivía en París. Al salir Darío de Nicaragua, iba investido con el cargo de ministro ante la corte de Alfonso XIII, y efectivamente presentó credenciales al último rey de España el día 2 de junio de rgo8. Por su investidura, debía permanecer en Madrid mientras los funcionarios del protocolo no lo autorizaran para moverse, pero puesto que el verano avanzaba y Darío, como cualquier otro mortal, tenía derecho a cambiar de aires, alejándose del tórrido calor madrileño, sale efectivamente de la corte. ¿A París? Nada de eso, al balneario de La Arena, en la costa de Asturias, donde permanece los meses de julio y agosto, cual puede probarse con la obvia 
cronología de algunos de sus escritos de entonces, especialmente los de la colaboración en $L a$ Nación de Buenos Aires. Y cuando termina la temporada veraniega, se va otra vez a la corte, donde tiene obligación funcionaria de residir mientras sea ministro diplomático. En r909, desde luego, publica en Madrid su relato del Viaje a Nicaragua, que hemos debido aducir antes, por las luces que arroja sobre el tema.

Debe notarse, a propósito, que D'Halmar, en su regreso de Calcuta, no pudo detenerse en Europa mucho tiempo a fin de hacerse cargo del consulado en Chiclayo, y que, en suma, no es fácil establecer que haya podido quedarse en París el tiempo justo para que lo encontrara Dario, en alguno de los viajes menores que éste hizo de Madrid. Todo esto porque, en el relato contenido en el folleto Rubén Dario y los americanos en París, queda perfectamente en claro que aquella tertulia funcionaba en la capital de Francia y no en la de España, y porque, en fin, el propio D'Halmar quiso darle otro emplazamiento cronológico. En el folleto citado, Rubén Dario y los americanos en París, Augusto d'Halmar contó la escena con bastante detalle, de modo que podría aceptarse, de estar a sus noticias, que el soneto necesariamente hubo de ser compuesto no antes de r9r2. Lo decimos así, porque D'Halmar por su parte afirma:

Habian fundado en Paris los hermanos Guido, los mismos que contrataron a Rubén para su desastrosa gira por América, la revista Mundial, y habíanla puesto bajo su dirección (p. 9).

Vimos ya que de los documentos administrativos copiados más arriba quedaba en claro cómo D'Halmar no había interrumpido, en ocho años, su permanencia dentro del servicio consular; pero hay mejores antecedentes para establecerlo así.

El día 30 de agosto de I9I 2 el escritor dirigió una carta a su amigo Salvador Smith, donde le decía:

Cuánto tiempo pasará todavía antes que volvamos a vernos. Yo no creo salit de aquí antes de dos años, para dirigirme a Europa, donde trataré de recuperar el tiempo perdido. De todas maneras y venga $U d$. a la capital o no, no me iré sin verlo.

El señor Smith creyó esta carta digna de la publicidad, y la publicó efectivamente en el periódico literario de Concepción Chantecler, edición del Io de febrero de igr 3 .

Pero dentro de ella hay un dato todavía más importante y decisivo, en nuestro entender, para zanjar el problema que llevamos entre manos. Casi al despedirse, D'Halmar decía: 
Yo conoci tan duramente la vida, mi querido amigo. Como la Durmiente del bosque, espero que cuando salga de aquí despertaré tan joven como llegué, hace cuatro años. Porque entre nuestra despedida donde Pulgar y ésta, han pasado cinco años, don Salvador.

Si en agosto de I9I2 D'Halmar acepta que han pasado cuatro años de su residencia en Chiclayo, es evidente que su llegada a ese puerto ha de fijarse en I908, como nosotros sabemos, y que no hubo en el intervalo viaje alguno que interrumpiera su estada en el puerto peruano.

Si se necesita una prueba accesoria para establecer cómo D'Halmar pasó directamente de la India al Perú, cuando fue nombrado para servir el consulado de Chiclayo, tal vez la encontremos en su relato "Gatita", publicado por primera vez en Los Diez (segundo número de la revista), después de haber sido leído por su autor en la velada de saludo que le dedicó al Ateneo de Santiago en Mayo de rgr6. La narración comienza diciendo: "De mi larga estadía en el Perú", expresión vaga, que podemos interpretar en muchas formas distintas. ¿Qué es larga? Si esto se escribe en rgr6 y D'Halmar, según suponemos, vivó en Chiclayo desde r9o8, largo sería el plazo de más de siete y de cerca de ocho años que media entre ambas fechas. Pero si seguimos leyendo, las dudas se aclaran considerablemente.

Había venido desde el Indostán a restablecer nuestro Consulado en Eten-escribe-, y por primera vez, después de treinta años desde que tuvinos la guerra, volvía a izarse la bandera de la estrella solitaria en esa alejada parte del país vencido, donde el odio se mantenía latente con la idea de la revancha $(p, 89)$.

Los "treinta años" de la referencia deben contarse desde I879, de modo que D'Halmar estaba en lo justo si se admite que en un escrito literario no caben precisiones mayores. Treinta años de la guerra se enteraron en 1909, es decir, muy pocos meses después del establecimiento del nuevo cónsul en Chiclayo.

Para precisar mejor que Thomson permaneció en su sede consular de Chiclayo entre I908 y I9I6, sin ninguna interrupción, pueden servir también los documentos consulares que se han publicado. Así lo vemos en los informes que envió al Ministerio de Relaciones Exteriores, conservados en el Archivo Nacional y otros, en menor número; insertos en el Boletin del Ministerio de Relaciones Exteriores, Culto y Colonización, publicación oficial que daba a luz exclusivamente documentos del servicio. Ahí hemos visto, por ejemplo, el Informe del Consulado de Chile en Chiclayo (Eten). Movimientos marítimo, comercial y administrativo 
en 1910, que ocupa las pp. Io9-20 del citado Boletín, número de febrero de I9Ir, y en seguida un Informe del Consulado de Cbile en Chiclayo, harto más reducido pues da cuenta sólo del movimiento de la oficina durante el primer trimestre de I9I I (pp. I87-9 del mismo Boletín).

En el terreno literario, no consular, conviene fijar también algunas fechas útiles para establecer dónde se hallaba Thomson. Solicitado por Ernesto Montenegro, desde Chile, para escribir sobre Pezoa Véliz algo que pudiera incluirse en Alma cbilena, Thomson escribió un Epílogo que alcanzó a publicarse en ese libro, con la firma D'Halmar y la siguiente fecha: "Eten, XI-2 ("La conmemoración de los fieles difuntos") IgI I". $\mathrm{Y}$, de otra parte, en el relato "El hijo de Juan Orth", incluido en Cristian y yo (Santiago, I946, pp. 348-55), la fecha al pie dice así: "Puerto Eten (Perú) 25 Agosto I9I4".

En la novela corta "Gatita", ya citada, hay asimismo precisiones que es ventajoso conocer. Después de haber descrito algunas escenas de su vida en Chiclayo y de presentar a Gatita en el ambiente que él quiso darle, el autor indica:

Fue esa misma altura la que escalamos para tratar de distinguir el cometa de 1910, el viernes 13 de mayo, me acuerdo, cuando todavía no amanecía (p. 98).

Finalmente, como otra prueba de que la vida de Thomson en el Perú no fue interrumpida por viaje alguno, he aquí otro pasaje de "Gatita":

Yo estaba aburrido y desanimado, cuando uno de esos despachos que, como los reciben los marinos se reciben en nuestra carrera, me hizo saber que debía decir adiós a mi deportación, para volver a ver la Europa. Toda la condena sufrida desaparecía como por ensalmo: yo era un hombre devuelto a la libertad, y esos años deprimentes del Perú se desvanecian como si no hubiesen sido nunca; volvía a encontrarme alegre y confiado como a mi llegada, Ileno de ambiciones y de esperanzas (p. 103).

De los antecedentes que hemos venido acopiando, queda establecido, en términos generales, que Augusto d'Halmar no encontró a Rubén Darío en Patís, en I908, a su regreso de la India, por la muy sencilla razón de que entonces Darío no estaba en París sino en Nicaragua; permaneció en Chiclayo, o Eten, puerto del Perú, desde que se hizo cargo del consulado, en I908, hasta que pidió licencia, en 1916 , y de consiguiente tampoco pudo encontrar a Dario en parte alguna entre esas dos fechas; que cuando se embarcó rumbo a Chile y cuando llegó a este país, ya Darío había fallecido. Esta observación nos indica, de otra parte, que 
en nada interesa a la averiguación que tenemos entre manos lo que el escritor haya hecho desde que salió de Chile en I9I6.

Habiendo podido salir de Chiclayo en virtud de la licencia de cuatro meses que se le concedió, Thomson se vino a Chile, y desembarcó en Valparaíso a fines del mes de abril de I9I6. Pronto pasó a Santiago, y en el acto pudo organizarse una velada para recibitlo en el Ateneo, donde leyó una producción en Chile no conocida, "Gatita". Véase la noticia que daba un diatio sobre aquella sesión del Ateneo, proyectada para el 3 de mayo:

El próximo miércoles, a las 9 P.M., celebrará el Ateneo la segunda sesión del presente año.

En ella leerá don Augusto Thomson un interesante trabajo literario sobre costumbres peruanas y don Pedro Prado dará a conocer algunos de sus nuevos poemas.

La parte musical estará a cargo de distinguidas alumnas del Conservatorio Nacional.

El director de turno, don Ricardo Montaner Bello, dará en nombre de la institución la bienvenida al joven literato que después de nueve años de labor en el extranjero, vuelve otra vez a ocupar la tribuna en que antes conquistara sus mejores triunfos. (Las. Ultimas Noticias, lunes $1^{9}$ de mayo de 1916).

Nuestra labor ha terminado respecto del primer punto. Hemos establecido con palabras del propio D'Halmar, que éste y Rubén Darío no fueron amigos, más aún: que nunca pudieron encontrarse. Nos queda por decir algo acerca del segundo punto: "En consecuencia, el soneto atribuido a Dario y que Augusto d'Halmar publicó con esa firma, no ha podido ser escrito por Rubén Darío".

Para facilitar el acceso del lector al problema evocado ante sus ojos, vamos a examinar en seguida algunos términos del soneto, a ver qué nos sugieren. "Encaneció muy joven", dice el soneto, lo que significa que cuando se le compone el escritor ya no es joven. Vistas las cosas de ótro ángulo, si en D'Halmar Darío no veía ya a un joven sino, a la inversa, a un hombre maduro, la entrevista o la amistad de los dos escritores debe ser emplazada no ya en I908, sino en alguna fecha posterior a ésta. Cuando el escritor chileno pasó la primera vez por Europa, en I908, era extremadamente joven, pues contaba sólo veintiséis o veintiocho años (según se acepten las fechas de nacimiento I882 y I880 que por lo común se indican para él), y su apariencia, además, contribuía a quitarle edad. Alto, rubio, espigado, de tez clara, bello de facciones, a todos daba la impresión de ser un adolescente lampiño. Es 
evidente, pues, que el autor del soneto - sea quien fuere- erró grandemente en esta alusión a las canas, con las cuales sin advertirlo se tapaba todos los caminos, esto es, se pasó de listo, que es más o menos lo habitual en los falsificadores.

Pero hay más. Imaginemos que alguien, llevado de extrema benevolencia, sugiere que el soneto fue compuesto en I908, es decir, cuando Thomson iba rumbo a la India para hacerse cargo de su consulado en Calcuta. Ya dijimos que entonces no pudo haber sido el encuentro, porque Dario no estaba en Europa sino en Nicaragua. Pues, además, el soneto no tiene asidero y es imposible desde el punto de vista literario. Augusto Thomson D'Halmar para las letras, al salir de Chile en I907 y al tocar París en I908, no tenía bagaje literario como para que Darío le escribiera un soneto, honor que este último reservó a muy pocas personas, como es fácil ver en la recopilación de sus obras. No era un literato de categoría; estaba recién comenzando su carrera. Darío podía ponerle dedicatoria en un epígrafe, como hizo con otros, pero no habría tenido qué decir de su obra, la cual en esas fechas se cifraba en una novela, Juana Lucero, y en algunas docenas de cuentos y artículos. La primera, la novela, no era como para inspirar sonetos a nadie; Ios otros, los trabajos sueltos de Thomson, no recogidos a libro, habría sido necesario leerlos en sus recortes, estudiarlos, compararlos, etc., antes de que Darío hubiera podido formarse impresión del alcance estético de aquel bagaje.

Dicho en síntesis: el soneto es absolutamente imposible, por motivos literarios, en I908. Ha debido ser, pues, escrito más adelante.

¿Pudo el soneto ser compuesto en IgI2 o en I9I3, si se toman al pie de la letra las palabras que hemos copiado más arriba, sobre la aventura de Mundial Magazine? Imposible, según las informaciones que en varios sitios hemos transcrito, y especialmente según lo que D'Halmar dice a su amigo Salvador Smith, esto es: que desde su establecimiento en Chiclayo no salió a parte alguna, y que para I9I4 ó I9I5 proyectaba irse a Europa, viaje que efectivamente emprendió en I9I6 y cuando ya Darío estaba muerto.

Augusto d'Halmar - ya lo vimos - afirmaba ante el Ministerio de Relaciones Exteriores no haber hecho uso de licencia durante ocho años, y como esto lo decía el último día de enero de rgr6, en consecuencia, por estar en Chiclayo (Perú), no pudo ver o encontrar a Darío ni en r9r5, ni en r9r4, ni en r9r3, ni en rgr2, ni en r9rI, ni en I9ro, ni en I909, ni en I908, que es precisamente cuanto hemos procurado demostrar. 
Después de lo ya expuesto, debe llamarse la atención a los escritores chilenos que traten monográficamente de Augusto d'Halmar hacia la conveniencia de no seguir atribuyendo a Rubén Darío el soneto discutido, el cual no puede ser suyo; prevención que cabría hacer igualmente extensiva a cuantos escriban sobre cualquier otro tema de las letras chilenas donde sea preciso citar a D'Halmar o estudiar el grupo de que éste formó parte. Una superchería de este calibre, y que compromete a un tercero, Rubén Darío, no puede ser acogida por quienes hayan podido seguir, en la exposición de documentos y en el alegato que se leyó antes, los efectivos antecedentes que rolan en el asunto. Hay un decoro literario elemental que así lo aconseja.

Yo acepto que es muy pintoresco el que Darío celebrara en verso $a$ un escritor chileno; y que, en fin, dentro de la capacidad fabuladora de D'Halmar, el inventar un soneto a quien, ya difunto, no puede probar que no lo escribió, sólo prueba la intensidad de su fantasía y el escaso respeto que por ello hubo de guardar el escritor chileno hacia lo que pudiéramos llamar el predio ajeno. Pero la verdad hay que conocerla, aunque duela, y esta vez la verdad está a la vista: Rubén Darío no pudo —entiéndase bien-, no pudo jamás escribir el soneto que D'Halmar le atribuyó.

De la Academia Chilena

RAỨl Sillva CASTRo 